\section{How to Meet Private Investors' Advisory Needs}

INDIVIDUAL INVESTORS DIFFER SUBSTANTIALLY IN THEIR ANALYTICAL SKILLS AND FINANCIAL KNOW-HOW, IN SHORT: IN THEIR FINANCIAL SOPHISTICATION. A SEGMENTATION STRATEGY BASED ON FINANCIAL SOPHISTICATION COULD INCREASE CUSTOMER SATISFACTION AND ACCEPTANCE OF ADVISOR RECOMMENDATIONS

ANDREAS HACKETHAL

CHRISTIAN JANSEN

\section{Need for financial advice}

The intense competition in global banking markets forces retail banks to differentiate via advisory quality. A solely sales-oriented strategy does not convince the increasingly demanding bank customer of today. Instead, comprehensive advisory concepts that focus on individual customer needs are in the center of innovative sales strategies. The potential for a value-add advisory is large: Abundant empirical evidence in Behavioral Finance shows that investors suffer from irrational investment decisions. For example, general stock market participation rates as well as the share of stocks in investors' portfolios are hardly commensurate with modern theories on portfolio selection. Moreover, portfolio diversification is often insufficient, especially in terms of geographic diversification. Investor behavior is frequently observed to be characterized by inertia, resulting in no or only sluggish portfolio adjustments to changes timal investment decisions generate nontridissatisfaction. It follows that financial advisory can be beneficial for investors if the consequence is the avoidance of suboptimal investment behavior. Importantly, not all investors suffer from irrational decision making to the same extent. Investors who possess better analytical skills and better financial knowledge are less prone to irrational behavior and suboptimal decision making than their less skilled peers. We use the term financial sophistication to capture these investor traits (see Figure 1). More sophisticated investors and those with little know-how differ quite substantially in their specific needs regarding the form and quality of financial advisory. As a consequence, advisors would have to treat the two investor types very differently in order to attain an optimal level of advisee acceptance of their advisory services. vial costs for investors and may also lead to
It also follows that conventional customer segmentation criteria such as age, wealth or income would not provide sufficient information for an advisor aiming to satisfy an investor's specific advisory needs. Retail banks that segment their customers based on sophistication and align their advisory processes accordingly could provide customers with a superior advisory quality and as a consequence, could be more effective in optimizing investor portfolios. This strategy is supported by regulative changes: The Markets in Financial Instruments Directive (MiFID) which will become effective in November 2007 sug gests that financial service providers (FSPs) align their financial advisory according to customer sophistication. In order to guaran- tee the suitability of transactions for the customer FSPs are required to assess in detail the financial situation, experience, and knowledge of their customers.

\section{Study of the advisory process}

In our study we empirically investigate whether a segmentation strategy that is based on individual financial sophistication has the potential to increase customer satisfaction. We surveyed 761 customers of two German retail banks and asked them to specify their last purchase of an investment product at their bank. Based on this specific purchase, we then queried customers on their satisfaction with the preceding advisory service in four categories: Satisfaction with the advisory

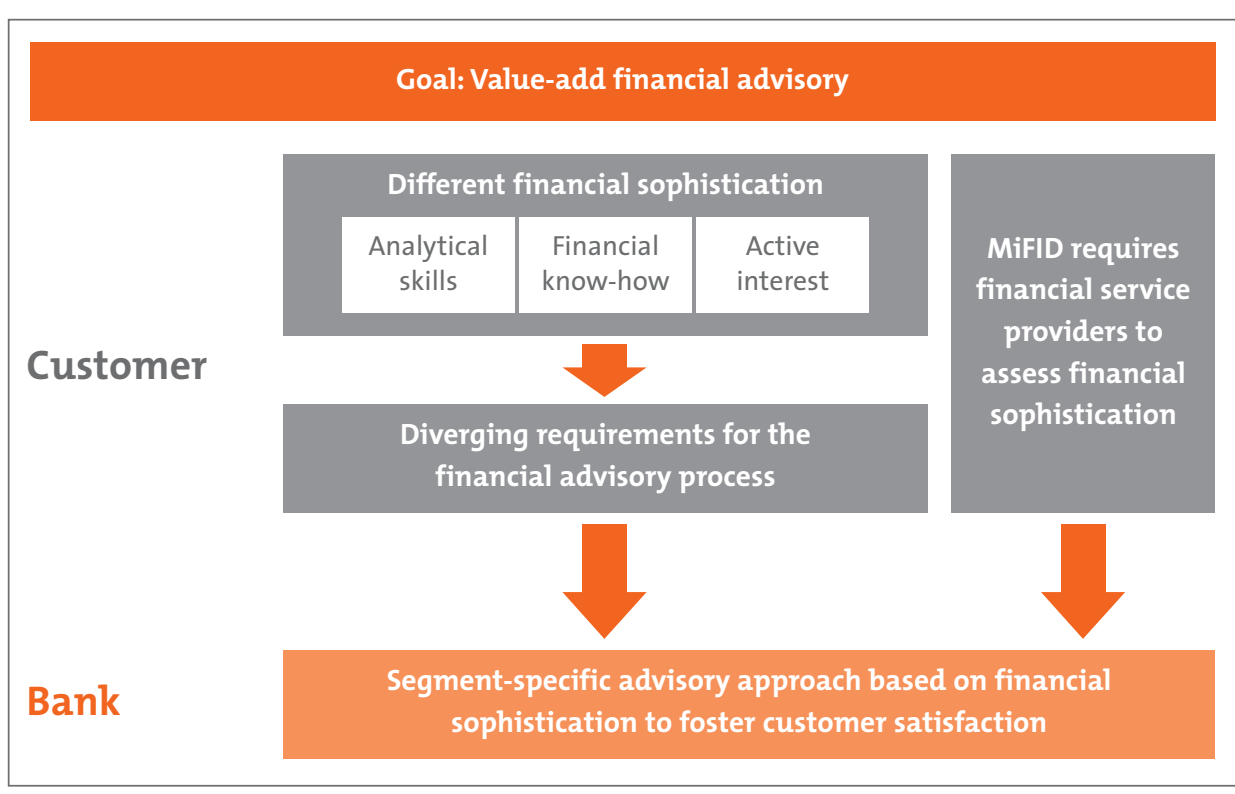

Figure 1: Segment-specific advisory to enhance customer satisfaction 
(65\% of respondents agreed), competence of advisor (73\% agreed), repurchase intentions (50\% would make the same purchase again), and recommendation behavior $15 \%$ recommended the service). Moreover, customers were asked to assess their perception of 30 attributes of that advisory service. The individual level of financial sophistication was evaluated using seven questions, e.g. on customers' affinity to finance, their financial knowledge and experience, and their rationality. Using cluster analysis we find that customers differ markedly in their level of financial sophistication.

\section{It depends on the customer type}

Based on logit-analysis we identified sixteen process attributes that have a significant impact on customer satisfaction. However, the large dispersion in customer perception

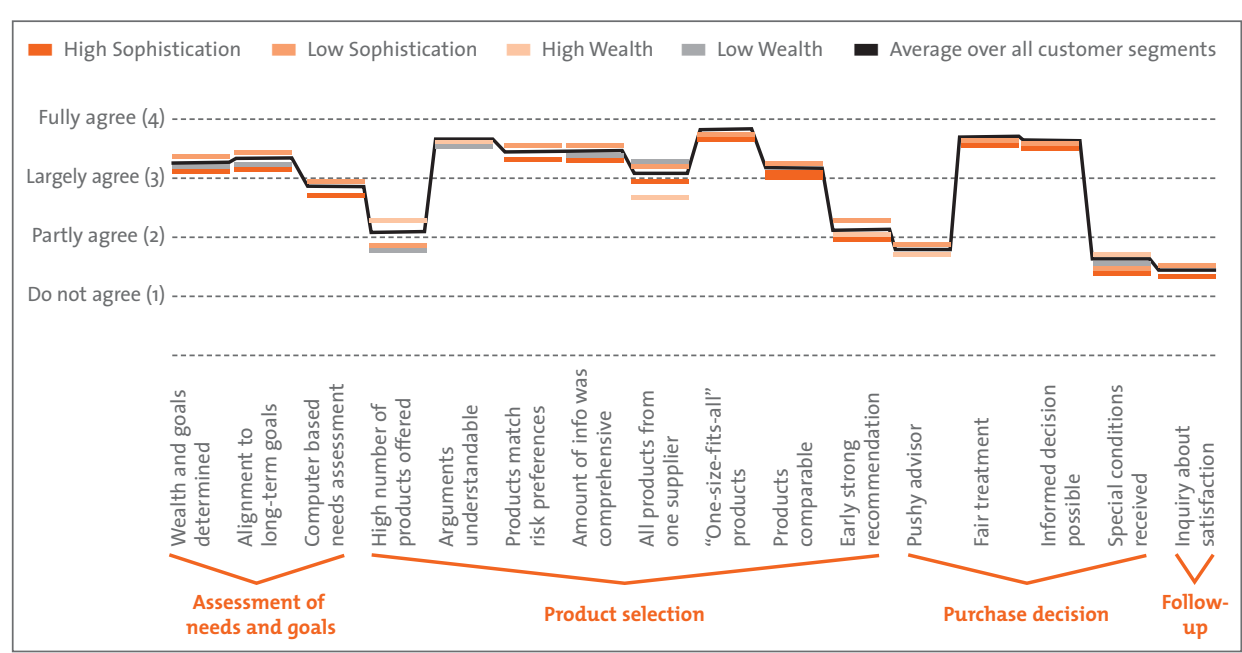

Figure 2: Customer perceptions of the advisory process of these process attributes indicates that customers are treated differently. The critical question is whether the observed differences are deliberate and systematic. To answer this question we compared average perceptions of process attributes of several customer segments (grouped by age, wealth, risk aversion, and financial sophistication). Figure 2 shows no systematic relationship between advisory process design and customer type. The observed unsystematic dispersion of customer perceptions might therefore be simply due to different advisor types who pursue their individual advisory style independent of the individual customer. However, cognitive characteristics of investors significantly affect their preferences for specific forms of financial advisory services. We estimated two separate logit models for each segmentation strategy and found that the two models for the largest deviations. Less sophisticated customers demand different characteristics for nine out of these sixteen attributes than their more sophisticated counterparts (see Figure 3). Less sophisticated investors tend to demand clear-cut recommendations and dislike complexity. Advisors should act as trustworthy guides who preprocess all relevant information and provide this group of advisees with only a small set of options to choose from. Our results indicate that advisors should not discuss at length potential behavioral biases of less sophisticated customers but instead encourage them to delegate their decision making to the advisor. Highly involved customers, on the other hand, seek a knowledgeable partner with whom they can jointly analyze a much broader set of options in order to improve their own decision making. More sophisticated investors might also appreciate education on behavioral biases because they are both more able and more willing to accept and act upon these insights. Finally, we estimated the hypothetical increase in customer satisfaction levels if the two retail banks adapted their advisory approaches to different sophistication levels. We find that a sophistication-oriented advisory would increase customer satisfaction by ca. $20 \%$.

\section{Conclusion}

Advisors who take into account investors' financial sophistication can increase customer acceptance of their recommendations and thereby better assist their advisees in improving their decision making. 